\title{
A JOINT PRICING AND NETWORK DESIGN MODEL FOR A CLOSED-LOOP SUPPLY CHAIN UNDER DISRUPTION (GLASS INDUSTRY)
}

\author{
Matineh Ziari@ and Mohsen Sheikh SajadieH*®
}

\begin{abstract}
Closed-loop supply chains have attracted more attention by researchers and practitioners due to strong government regulations, environmental issues, social responsibilities and natural resource constraints over past few years. This paper presents a mixed-integer linear programming model to design a closed-loop supply chain network and optimizing pricing policies under random disruption. Reusing the returned products is applied as a resilience strategy to cope with the waste of energy and improving supply efficiency. Moreover, it is necessary to find the optimal prices for both final and returned products. Therefore, the model is formulated based on demand function and it maximizes total supply chain's profit. Finally, its application is explored through using the real data of an industrial company in glass industry.
\end{abstract}

Received November 13, 2019. Accepted January 3, 2022.

\section{INTRODUCTION}

The globalization of economic activities along with rapid improvement of information technology in recent years result in shorter circulation of life cycles, smaller transportation capacity and customer's dynamic behavior in terms of choices and demands. This causes the demands to be insecure and increases the significance of supply chain design, consequently. Supply chain network design (SCND) is considered as one of the most important strategic decisions in supply chain management. These decisions will greatly influence the effectiveness and productivity of each organization. SCND includes determining the location and number of facilities available in the network, the inventory of each facility and the quantity of flows between facilities. The goal of SCND is to minimize the operational costs such as purchase, production, transportation, inventory, and etc [16]. Moreover, in the last decades supply chain drew more attentions, considering environmental concerns, governmental laws and natural resources restrictions [6]. Therefore, it seems essential to study and analyze the effect of integrated network design on cost reduction.

Nowadays, various types of systems, from the simplest to the most complicated ones become an inseparable part of human's life [7]. The problem of systems failure presenting as disruption can be a serious threat to a society or environment and results in catastrophic damages. The supply chain as a complicated system is not an exception. The disruptions in supply chain are unplanned and unpredictable events which spoils the normal

Keywords. Pricing, network design, closed-loop supply chain, disruption.

Department of Industrial Engineering and Management Systems, Amirkabir University of Technology, Tehran, Iran.

* Corresponding author: sajadieh@aut.ac.ir 
process of materials [12]. Therefore, it puts the supply chain companies in danger of finance and operational risks.

\section{Literature REVIEW}

In this section, we review studies in two separate but complementary research streams: closed-loop supply chain network design models and the problems developed for dealing with disruption risks.

Fleischmann et al. [11] were the first practitioners that developed an integrated logistic network. They considered forward flow along with reverse flow in a hybrid production/recovery and collection/distribution network. Salema et al. [33] generalized their work and presented a model for designing a reverse logistic network to optimize the forward and reverse flows. They presented a general model using stochastic mixed-integer programming approach.

$\mathrm{Lu}$ and Bostel [23] proposed a location problem with different types of facilities that should be located in a remanufacturing network. They proposed a MIP model considering both forward and reverse flows with their interactions. A lagrangian-based heuristic method was then developed to solve the problem.

Listeş and Dekker [22] developed a scenario-based stochastic programming model to design an integrated supply chain network. A decomposition method was used for solving the model in large-sized instances based on branch-and-cut procedure. Pishvaee et al. [26] suggested a bi-objective MILP model that includes maximizing the network responsiveness and minimizing the total costs in a closed-loop supply chain network. Afterwards, a Memetic algorithm was developed to solve the proposed model.

Pishvaee and Torabi [25] presented a bi-objective possibilistic MIP model to deal with inherent uncertainty of input data. The proposed model integrated the network design decisions in forward and reverse flows, and incorporated the strategic decisions along with tactical ones to avoid the sub-optimality. To solve the model, an interactive fuzzy solution approach was developed by combining a number of solution approaches. Later, Pishvaee et al. [27] developed a robust optimization model for handling the inherent uncertainty of input data in a closed-loop SCND problem. First, a deterministic MLP model was studied to design a CLSCND. Then, the model robust counterpart was obtained by using recent extensions in robust optimization theory.

Ramezani et al. [30] studied a robust model for a multi-echelon, multi-product, closed-loop logistic network under uncertain environment. As, logistic network design is a time consuming and costly project, a robust optimization approach was developed to mitigate demand and return rate uncertainties described by a finite set of possible scenarios. Hence, they applied scenario relaxation algorithm to find the robust solutions.

Qiang et al. [29] examined a CLSCN with decentralized decision-makers including suppliers, retail outlets, and the manufacturers who are responsible for collecting the recycled products from the market. Proposing a bi-objective CLSC network was another attempt in this area done by Amin and Zhang [2]. They investigated a CLSC network including multiple plants, collection centers, demand markets, and products. To this aim, an MILP model was formulated to minimize the total cost. Lin et al. [21] considered delivery spoilage for evaluating the reliability of a stochastic network. Finally, they used a heuristic algorithm to assess the network reliability.

Ramezani et al. [31] addressed the application of fuzzy sets for designing a multi-product, multi-period closedloop supply chain. The proposed chain includes three objective functions: profit maximization, delivery time minimization and quality maximization. Özceylan et al. [24] described an integrated model jointly optimizes the strategic and tactical decisions of a CLSC network. They aimed to minimize the associated costs including transportations, purchasing, refurbishing and operating the disassembly workstations. Then, an MINLP model was described for the developed problem.

Keyvanshokooh et al. [18] used dynamic pricing approach for returned products in an integrated forward/reverse logistic network design problem. The model was multi-echelon, multi-period and multi-commodity where the returned products are categorized with respect to their quality levels. The objective was to minimize total costs using an MIL model. Computational results indicated that dynamic pricing approach has more acceptable solutions than using static pricing. Demirel et al. [8] proposed an MILP model for a multi-period 
CLSCND problem. They used two distinct policies, secondary market pricing and incremental incentive strategy. Finally, a genetic algorithm was developed to solve the real size problems.

Regarding disruption in closed-loop supply chain network, Qi et al. [28] studied an integrated SCND problem to determine retailers' locations and the assignments of customers to retailers in order to minimize the location, transportation, and inventory costs. They considered random disruptions in their system, which may occur at either supplier or retailer. The problem was considered to be single-period and single-product in a certain environment. Hatefi et al. [15] proposed a model for reliable design of an integrated forward-reverse logistic network and used reliability concepts to deal facility disruptions. Unreliable hybrid facilities were partially disrupted but their remaining capacities can still serve customers. Moreover, sharing strategy was applied for compensating the lost capacity at unreliable facilities.

Vahdani et al. [36] presented a model to design a reliable network under uncertainty. To this aim, a biobjective mathematical programming formulation was proposed to minimize total costs. A new hybrid solution methodology was then constructed to solve the model by combining robust optimization method, queuing theory and fuzzy multi-objective programming approach.

Hatefi and Jolai [14] suggested a reliable and robust model for an integrated forward-reverse logistics network design considering uncertain parameters and facility disruptions. The proposed model was formulated based on robust optimization method to strength the network over uncertainty. The proposed network was single-period, single-product and multi-echelon including production and distribution centers in forward stream; and collection, recovery and disposal centers in reverse flow. Later, Yadegari et al. [38] proposed an integrated logistics network model by considering various kinds of transportation modes. They also utilized a Memetic algorithm to solve the proposed model.

Aryanezhad et al. [3] investigated a SCND problem where distribution centers are facing random disruptions. The proposed model was formulated as an MINLP model to minimize expected total costs including location, inventory, transportation costs and lost sales. To solve the model, an efficient solution approach based on genetic algorithm was developed. Azad et al. [5] proposed a capacitated SCND model under random disruptions in facilities and transportation routes. The model objective was to determine the optimal locations of distribution centers and the best assignment of costumers to each opened distribution center. Tahirov et al. [34] proposed a new model for recovering the disassembled parts in a specific chain. They examined the pure policy to obtain the most suitable strategy after analyzing the model behavior through some numerical examples. Keyvanshokooh et al. [18] studied a profit maximization model for the CLSCND problem in an MILP formulation by considering flexibility on collected returns and satisfied demand.

They developed the past researches by presenting a new method, which incorporates different kinds of uncertainties, simultaneously. Farrokh et al. [10] presented a CLSCND problem under hybrid uncertainty. The first type considered, was the uncertainty of future scenarios and the other one, the imprecise nature of each parameter' value. Finally, two approaches were applied to mitigate the uncertainty.

Hasani and Khosrojerdi [13] examined an MIP model to design a robust global supply chain by proposing different resilience strategies for handling considered disruption risks. They also presented a Taguchi-based Memetic algorithm for obtaining a suitable set of neighborhood structures. Table 1 reviews the most relevant papers about the supply chain network design problem considering pricing decisions under disruption risks and also highlights the main contributions of the current paper.

As can be seen, most of CLSCND problems did not examine the disruption and unavailability of facilities in their model, i.e. they assume that facilities are always available. Moreover, in a few papers the price of returned products and shortage is considered, simultaneously. The present paper differs from the existing studies in the field of CLSC network design by considering risks of disruption and optimization of final and returned products' prices. More specifically, the model takes the risks of disruption into consideration in designing phase of a multi-period and multi-product CLSC network design. The remainder of this paper is organized as follows: In Sections 3, the problem is defined and formulated. The computational results and sensitivity analyses are reported in Section 4. Finally, conclusions and future research directions are explained in the last section. 
TABLE 1. Brief data on the most relevant papers in literature.

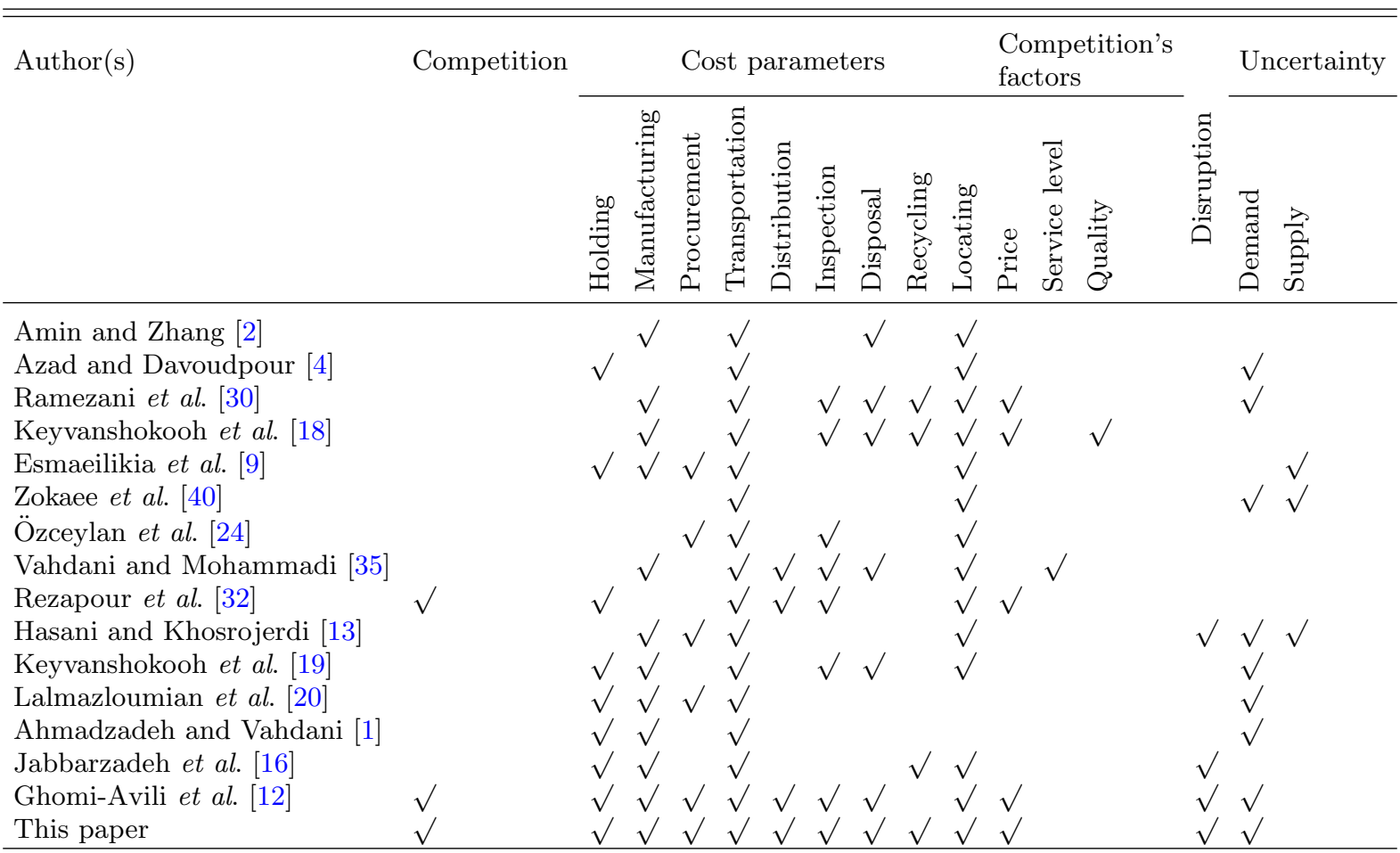

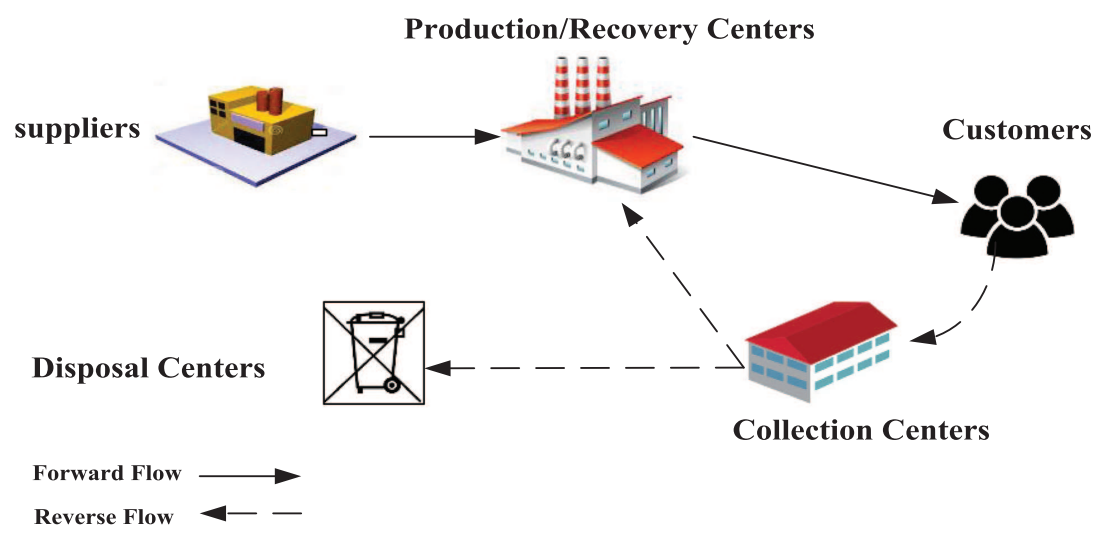

Figure 1. Structure of market to market closed-loop supply chain network.

\section{Problem definition}

This paper considers a CLSCN including suppliers, production/recovery, and collection and disposal centers with different customers, i.e. multi-echelon, multi-product and multi-period supply chain. The objective is to increase market demand, improve the system responsiveness and reduce costs. As shown in Figure 1, flows from supplier and from customers are used for production. The returned products are first collected in the collection centers and after testing the recoverable products, are shipped to production/recovery centers. Afterwards, 
the scrapped products are shipped to disposal centers. The recovered products are then shipped to consumers (referred to as B2B). In other flow, raw materials are shipped from suppliers to production/recovery centers and then to customers. According to market research, the main disruption influencing the whole supply chain is related to the production center for reasons such as changing the format, machine's failure, air pressure drop, power outage, etc. In other words, hybrid production/recovery centers are under random disruption scenarios. Furthermore, the effect of rising the price of returned product and reducing the price of final products is studied. Figure 1 illustrates the network and flows between different echelons.

The following assumptions are considered through this paper to simplify the modeling efforts:

- The problem is assumed to be multi-product and multi-period.

- All of the returned products are collected from customers.

- Shortage is allowed.

- Location of suppliers, customers and disposal centers are fixed and predefined.

- Location of collection centers and production/recovery centers are changeable.

- Number of facilities (that can be opened) and their capacities are limited.

- Quantity of returned products and average disposal rate are given in advance.

- Partial disruption parameters are uncertain and described by a set of scenarios.

- Capacity of the collection, production/recovery and disposal centers are limited.

- Each production/recovery center has a probability of failure and multiple production/recovery centers can fail, simultaneously.

Considering the above assumptions, the objective is to optimize the price of final and returned products, locations and numbers of hybrid collection and production/recovery centers as well as quantity of flows between facilities of different echelons and customer zones.

\subsection{Model formulation}

The model involves the following sets, parameters and decision variables.

\section{Sets}

$P \quad$ Set of suppliers, $p=1, \ldots, P$

$M \quad$ Set of disposal centers, $m=1, \ldots, M$

$K \quad$ Set of customer zones, $k=1, \ldots, K$

$J \quad$ Set of potential locations for production/recovery centers, $j=1, \ldots, J$

$C$ Set of potential locations for collection centers, $c=1, \ldots, C$

$S \quad$ Set of scenarios, $s=1, \ldots, S$

$T \quad$ Set of time periods (months), $t=1, \ldots, T$

$I \quad$ Set of product types, $i=1, \ldots, I$

$N$ Set of raw materials from the forward flow, $n=1, \ldots, N$

$G$ Set of raw materials from the reverse flow, $g=1, \ldots, G$

\section{Parameters}

$\mathrm{cap}_{j} \quad$ Capacity of handling products at production/recovery center $j$

$f c_{c} \quad$ Fixed cost of opening collection center $c$

$f c_{j}^{\prime} \quad$ Fixed cost of opening production/recovery center $j$

$\gamma \quad$ Average disposal fraction of product

$\overline{c r}_{p} \quad$ Capacity of supplier $p$

$\mathrm{cap}_{m} \quad$ Capacity of handling scrapped products at disposal center $m$

$c a m_{j}$ Capacity of handling raw materials at production/recovery center $j$

$c p_{j} \quad$ Production capacity of production/recovery center $j$

$g_{k c i t}^{\prime} \quad$ Transportation cost per unit of returned product $i$ from customer $k$ to collection center $c$ at period $t$ 
$e_{c j i t} \quad$ Transportation cost per unit of recoverable product $i$ from collection center $c$ to production/recovery center $j$ at period $t$

$q_{c m i t}$ Transportation cost per unit of scrapped product $i$ from collection center $c$ to disposal center $m$ at period $t$

$b_{j k i t}$ Transportation cost per unit of product $i$ from production/recovery center $j$ to customer zone $k$ at period $t$

$a_{n p j t}$ Transportation and purchase cost of raw materials $n$ from supplier $p$ to production/recovery center $j$ at period $t$

$h c_{j i t} \quad$ Product handling cost $i$ at production/recovery center $j$ at period $t$

$w e i_{n i} \quad$ Weight of raw material $n$ used in product $i$

rwei $_{\text {gi }}$ Weight of raw material (glass) used in product $i$

$w e_{i} \quad$ Weight of glass obtained from product $i$

$l_{k i t}^{s} \quad$ Base market demand of customer customer $k$ for product $i$ in period $t$ in scenario $s$

$\sigma \quad$ Sensitivity of market demand to the price of returned products

$\xi \quad$ Sensitivity of market demand to the price of final products

$\beta \quad$ Percent of customers returning used products to the collection centres

$p c_{j i} \quad$ Production cost of product $i$ from raw materials at production/recovery center $j$

$\overline{p c}_{j i} \quad$ Production cost of product $i$ from reverse flow at production/recovery center $j$

$\eta_{j t}^{s} \quad$ Disruption percentage; 0 if no disruption happens, 1 if fully disrupted and $[0,1]$ when facing partial disruption

$\pi_{s} \quad$ Probability of scenario $s$

\section{Decision variables}

$\tau_{k i t}^{s} \quad$ Returns of used products type $i$ from customer $k$ at period $t$ in scenario $s$

$d_{k i t}^{s} \quad$ Demand of customer $k$ for product $i$ in period $t$ in scenario $s$

$X_{n p j t}^{s} \quad$ Quantity of raw materials $n$ from supplier $p$ to production/recovery center $j$ at period $t$ in scenario $s$

$F_{j k i t}^{s} \quad$ Quantity of products $i$ shipped from production/recovery center $j$ to customer zone $k$ at period $t$ in scenario $s$

$\bar{R}_{k c i t}^{s} \quad$ Quantity of returned products $i$ shipped from customer zone $k$ to collection center $c$ at period $t$ in scenario $s$

$H_{c j i t}^{s} \quad$ Quantity of recoverable products $i$ shipped from collection center $c$ to production/recovery center $j$ at period $t$ in scenario $s$

$Q_{j i t}^{s} \quad$ Quantity of products $i$ produced from raw materials at production/recovery center $j$ at period $t$ in scenario $s$

$U_{j i t}^{s} \quad$ Quantity of products $i$ produced from reverse flow at production/recovery center $j$ at period $t$ in scenario $s$

$Y_{c m i t}^{s} \quad$ Quantity of scrapped products $i$ shipped from collection center $c$ to disposal center $m$ at period $t$ in scenario $s$

$\mathrm{QI}_{j i t}^{s} \quad$ Inventory level of product $i$ at production/recovery center $j$ at the end of period $t$ in scenario $s$

$W_{k i t}^{s} \quad$ Price of final products

$Z_{k i t}^{s} \quad$ Price of returned products

$\omega_{j} \quad$ Binary variable equals to 1 if production/recovery center $j$ is opened, 0 otherwise

$\psi_{C} \quad$ Binary variable equals to 1 if collection center $c$ is opened, 0 otherwise

In terms of above notation, the CLSCND problem can be formulated as follows:

$$
\begin{aligned}
\operatorname{Max} Z= & \sum_{k} \sum_{i} \sum_{t} \sum_{s} \pi_{s} W_{k i t}^{s} d_{k i t}^{s} \pm-\left(\sum_{j} f c_{c}^{\prime} \omega_{j}+\sum_{c} f c_{j} \psi_{c}\right. \\
& +\sum_{k} \sum_{c} \sum_{i} \sum_{t} \sum_{s} \pi_{s} Z_{k i t}^{s} \bar{R}_{k c i t}^{s}+\sum_{l} \sum_{c} \sum_{i} \sum_{t} \sum_{s} \pi_{s} g_{k c i t}^{\prime} \bar{R}_{k c i t}^{s}
\end{aligned}
$$




$$
\begin{aligned}
& +\sum_{c} \sum_{j} \sum_{i} \sum_{t} \sum_{s} \pi_{s} e_{c j i t} H_{c j i t}^{s}+\sum_{j} \sum_{k} \sum_{i} \sum_{t} \sum_{s} \pi_{s} b_{j k i t} F_{j k i t}^{s} \\
& +\sum_{n} \sum_{p} \sum_{j} \sum_{t} \sum_{s} \pi_{s} a_{n p j t} X_{n p j t}^{s}+\sum_{c} \sum_{m} \sum_{i} \sum_{t} \sum_{s} \pi_{s} q_{c m i t} Y_{c m i t}^{s} \\
& +\sum_{j} \sum_{i} \sum_{t} \sum_{s} \pi_{s} p c_{j i t} Q_{j i t}^{s}+\sum_{j} \sum_{i} \sum_{t} \sum_{s} \pi_{s} \overline{p c}_{j i t} U_{j i t}^{s} \\
& \left.+\sum_{j} \sum_{i} \sum_{t} \sum_{s} \pi_{s} h c_{j i t} \mathrm{QI}_{j i t}^{s}\right) \\
& \sum_{j} F_{j k i t}^{s}=d_{k i t}^{s} \\
& \sum_{c} \bar{R}_{k c i t}^{s}=\tau_{k i t}^{s} \\
& \sum_{j} H_{c j i t}^{s}-(1-\gamma) \sum_{k} \bar{R}_{k c i t}^{s}=0 \\
& \sum_{m} Y_{c m i t}^{s}-\gamma \sum_{k} \bar{R}_{k c i t}^{s}=0 \\
& \sum_{l} \bar{R}_{l c i t}^{s} \leq \operatorname{cap}_{c} \psi_{c} \\
& \sum_{p} \sum_{n} X_{n p j t}^{s}+\sum_{c} \sum_{i} H_{c j i t}^{s} w e_{i} \leq \operatorname{cam}_{j} \omega_{j} \\
& \sum_{c} Y_{c m i t}^{s} \leq c a p_{m} \\
& \mathrm{QI}_{j i, t-1}^{s}+O_{j i t}^{s}+U_{j i t}^{s}-\sum_{k} F_{j k i t}^{s}=\mathrm{QI}_{j i t}^{s} \\
& \sum_{i} \mathrm{QI}_{j i t}^{s} \leq \operatorname{cam}_{j} \omega_{j} \\
& \sum_{i} O_{j i t}^{s} w e i_{m i} \leq \sum_{p} X_{n p j t}^{s} \\
& \sum_{i} U_{j i t}^{s} r w e i_{g i} \leq \sum_{c} \sum_{i} H_{c j i t}^{s} w e_{i} \\
& \sum_{i} O_{j i t}^{s}+\sum_{r} U_{j i r t}^{s} \leq c p_{j}\left(1-\eta_{j t}^{s}\right) \omega_{j} \\
& \sum_{k} F_{j k i t}^{s} \leq O_{j i t}^{s}+U_{j i t}^{s}+\mathrm{QI}_{j i(t-1)}^{s} \\
& \sum_{j} X_{n p j t}^{s} \leq \overline{c r}_{p} \\
& d_{k i t}^{s}=l_{k i t}^{s}+\sigma Z_{k i t}^{s}-\xi W_{k i t}^{s} \\
& \tau_{k i t}^{s}=\beta d_{k i t}^{s} \\
& \bar{R}_{k c i t}^{s}, H_{c j i t}^{s}, X_{n p j t}^{s}, F_{j k t}^{s}, Y_{c m i t}^{s}, \mathrm{QI}_{j i t}^{s}, Q_{j i i}^{s}, U_{j i t}^{s}, \tau_{k i t}^{s}, d_{k i t}^{s}, W_{k i t}^{s}, Z_{k i t}^{s} \geq 0 \\
& \omega_{j}, \psi_{c} \in\{0,1\}
\end{aligned}
$$


The objective function (3.1) maximizes the total profit of the proposed network. It includes total incomes minus operational costs of opening production/recovery center, costs of opening collection center, and operational costs of purchasing returned products, transportation costs of returned product from customers to collection center, transportation costs of recoverable products from collection centers to production/recovery centers, transportation costs of products from production/recovery center to customers, transportation costs of raw material from suppliers to production/recovery centers, transportation costs of scrapped products from collection centers to disposal centers, production costs of products from direct flow at production/recovery centers, productions costs of products from reverse flow at production/recovery center and handling costs of recoverable products at production/recovery centers. Constraints (3.2) assure that all customers' demands are considered. Constraints (3.3) enforce that all of the returned products are collected. Constraints (3.4) and (3.5) represent the flow balance at collection centers. Constraints (3.6)-(3.8) state the capacity constraints of collection, production/recovery and disposal center. Constraints (3.9) show the balance of inventory at production/recovery centers and update inventory level at production/recovery centers (It means that the total inventory in time $t$ is equal to the total amount of inventory in $t-1$ plus the produced products from direct and reverse flow subtracted by the total amount of delivered products). Constraints (3.10) show that inventory level at each production/recovery center must be less than each center's capacity. Constraints (3.11) and (3.12) show raw material usage at each forward and reverse flow. Constraints (3.13) state production capacity of production/recovery centers due to different disruption scenarios. Constraints (3.14) assure inventory balance at production/recovery centers. Constraints (3.15) express capacities for suppliers with minimum required efficiency. Constraints (3.16) and (3.17) calculate customer demand and returned products [39]. Constraints (3.18) and (3.19) enforce binary and non-negativity restrictions on corresponding decision variables.

\subsection{Linearization}

As two continuous variables are multiplied to each other in objective function $\left(Z_{k i t}^{s} \bar{R}_{k c i t}^{s}\right.$ and $\left.W_{k i t}^{s} d_{k i t}^{s}\right)$, the model is nonlinear. For linearization of the model, we use the approach introduced by Vidal and Goetschalckx [37]. In this approach, first a lower and then an upper bound should be determined for each of the multiplied continuous variables. Here the established bounds are derived based on historical data of the Glass industry. The average estimator is used for finding the proper bounds of each variable. However, in case of not having any historical data, the following method can be used. First, the simple model must be solved without pricing concept and defining market-based demand. Then, pricing variables and the consequent constraints should be added to the simple model. As, the optimal values cannot be better than the previous case by adding extra constraints, the optimal values of the simple model can be used as the bounds for the new proposed one. Constraints (3.20)-(3.23) determine the lower and the upper bound for variables $Z_{k i t}^{s}, \bar{R}_{k c i t}^{s}$, $W_{k i t}^{s}$ and $d_{k i t}^{s}$, respectively.

$$
\begin{aligned}
& \mathrm{LB}_{k c i t} \leq \bar{R}_{k c i t}^{s} \leq \mathrm{UB}_{k c i t} \\
& \mathrm{LB}^{\prime} \leq Z_{k i t}^{s} \leq \mathrm{UB}^{\prime} \\
& \overline{\overline{\mathrm{LB}}}_{k i t} \leq d_{k i t}^{s} \leq \overline{\overline{\mathrm{UB}}}_{k i t} \\
& \mathrm{LB}^{\prime \prime} \leq d_{k i t}^{s} \leq \mathrm{UB}^{\prime \prime}
\end{aligned}
$$

$$
\begin{aligned}
& \forall k, c, i, t, s \\
& \forall k, i, t, s \\
& \forall k, i, t, s \\
& \forall k, i, t, s .
\end{aligned}
$$

Then, the nonlinear phrases are replaced by new continuous variables:

$$
\begin{array}{ll}
\phi_{k c i t}^{s}=Z_{k i t}^{s} \bar{R}_{k c i t}^{s} & \forall k, c, i, t, s \\
\theta_{k c i t}^{s}=W_{k i t}^{s} d_{k i t}^{s} & \forall k, i, t, s .
\end{array}
$$

The following constraints should then be added to the model:

$$
\begin{array}{ll}
\mathrm{LB}_{k c i t} Z_{k i t}^{s} \leq \phi_{k i t}^{s}=\mathrm{UB}_{k c i t} Z_{k i t}^{s} & \forall k, c, i, t, s \\
\mathrm{LB}^{\prime} \bar{R}_{k c i t}^{s} \leq \phi_{k i t}^{s}=\mathrm{UB}^{\prime} \bar{R}_{k c i t}^{s} & \forall k, i, t, s
\end{array}
$$




$$
\begin{array}{ll}
\overline{\overline{\mathrm{LB}}}_{k i t} W_{k i t}^{S} \leq \theta_{k i t}^{s}=\overline{\overline{\mathrm{UB}}}_{k i t} W_{k i t}^{S} & \forall k, i, t, s \\
\mathrm{LB}^{\prime \prime} d_{k i t}^{s} \leq \theta_{k i t}^{s}=\mathrm{UB}^{\prime \prime} d_{k i t}^{s} & \forall k, i, t, s .
\end{array}
$$

The linear model can then be written as follows:

$$
\begin{aligned}
\max \text { Profit }= & \sum_{k} \sum_{i} \sum_{t} \sum_{s} \pi_{s} \theta_{k i t}^{s}-\left(\sum_{j} f c_{j} \omega_{j}+\sum_{c} f c_{c}^{\prime} \psi_{c}+\sum_{k} \sum_{c} \sum_{i} \sum_{t} \sum_{s} \pi_{s} \phi_{k c i t}^{s}\right. \\
& +\sum_{l} \sum_{c} \sum_{i} \sum_{t} \sum_{s} \pi_{s} g_{k c i t}^{\prime} \bar{R}_{k c i t}^{s}+\sum_{c} \sum_{j} \sum_{i} \sum_{t} \sum_{s} \pi_{s} e_{c j i t} H_{c j i t}^{s}+\sum_{j} \sum_{k} \sum_{i} \sum_{t} \sum_{s} \pi_{s} b_{j k i t} F_{j k i t}^{s} \\
& +\sum_{n} \sum_{p} \sum_{j} \sum_{t} \sum_{s} \pi_{s} a_{n p j t} X_{n p j t}^{s}+\sum_{c} \sum_{m} \sum_{i} \sum_{t} \sum_{s} \pi_{s} q_{c m i t} Y_{c m i t}^{s}+\sum_{j} \sum_{i} \sum_{t} \sum_{s} \pi_{s} p c_{j i t} O_{j i t}^{s} \\
& \left.+\sum_{j} \sum_{i} \sum_{t} \sum_{s} \pi_{s} \overline{p c}_{j i t} U_{j i t}^{s}+\sum_{j} \sum_{i} \sum_{t} \sum_{s} \pi_{s} h c_{j i t} \mathrm{QI}_{j i t}^{s}\right)
\end{aligned}
$$

Constraints (3.2)-(3.19), (3.20)-(3.23) and (3.26)-(3.29).

\section{CASE STUDY}

In this section, we study an industrial case of a Glass Company established in 1975 with the participation of Bank of Mine and Industry (The same case problem is also studied by Jabbarzadeh et al. [16] who mainly focused on mitigating operational and disruption risks in a closed-loop supply chain using robust optimization). In 1982, a capacity of 20000 tons per year was exploited. The company's products now include bottle of lemon juice, syrup, alcohol, beverages and liquid oil (in various volumes) and soda glass, milk glass, sauce, jam, pickles and tomato, and a lot of special glasses based on customer's orders. It is trying to enter domestic and foreign competition and is seeking to build more plants. For this purposes, as can be seen in Figure 2, they consider five more places for locating new plants.

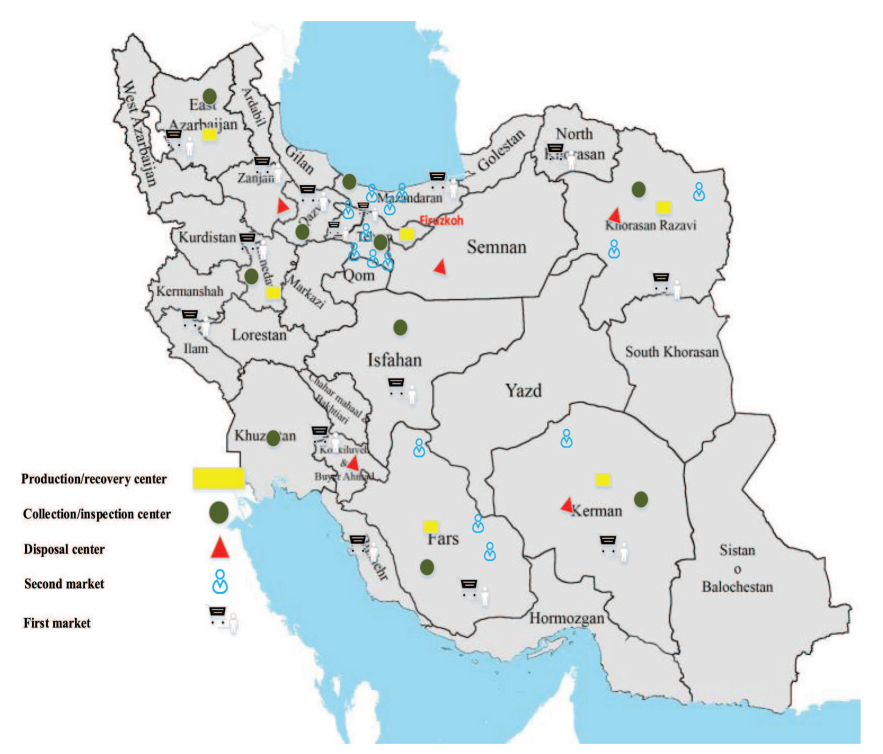

Figure 2. The location of different nodes in the company [16]. 
TABLE 2. Differences between results of the proposed model and the real case problem.

\begin{tabular}{lllll}
\hline \hline \multirow{2}{*}{ Sample } & \multirow{2}{*}{ Size } & \multicolumn{3}{c}{ Total cost (Billion rials) } \\
\cline { 3 - 5 } & & Proposed model & Real cost & Cost saving \\
\hline 1 & $(3,7,7,1,3,4,6)$ & 0.968 & 0.976 & 0.010 \\
2 & $(3,5,2,1,7,4,9)$ & 0.943 & 0.954 & 0.011 \\
3 & $(4,4,2,2,3,4,8)$ & 1.076 & 1.082 & 0.006 \\
4 & $(5,6,7,1,3,4,10)$ & 1.021 & 1.024 & 0.003 \\
5 & $(3,7,5,3,3,4,8)$ & 1.580 & 1.603 & 0.023 \\
6 & $(5,7,3,1,3,4,5)$ & 1.729 & 1.778 & 0.050 \\
7 & $(4,7,2,1,3,4,7)$ & 18.450 & 18.626 & 0.176 \\
8 & $(3,7,7,1,3,4,10)$ & 27.794 & 27.890 & 0.096 \\
9 & $(4,5,6,1,3,4,9)$ & 40.537 & 41.811 & 1.274 \\
10 & $(4,6,5,1,3,4,10)$ & 62.332 & 62.410 & 0.078 \\
\hline
\end{tabular}

According to high costs of supplying raw materials from mines and existing constraints, company is seeking to collect its productions from customers and supply new products to them both for reducing costs and preserving the environment and natural resources. Thus, it should establish some new facilities as collection centers to collect products, and disposal centers to scrap useless products. To this end, it has considered five places to build collection centers and three places for disposal centers around the country. Due to restrictions, the company wants to see which of these places are suitable for establishing facilities to be cost-effective and more suitable for collecting products for enhancing systems' responsiveness. Moreover, high risks of disruption in region (e.g. the risks of earthquakes and floods) have persuaded them to seek a more reliable supply chain network. Likewise, lower costs of producing glass items through returned products justifies the redesign of the supply chain network.

Thus, some part of data including the capacity of existing facilities, opening costs of collection centers and the associated cost of producing or handling of products are directly used from this case problem. Nevertheless, there was not any historical data or special records on the sensitivity of market demand to the prices or the rate of returned products, these parameters are set based on the expert managers' opinion in the glass industry. The model is solved by GAMS 24.3/CPLEX. According to the case problem, there are three suppliers, five production centers, five collection centers, three disposal centers, 10 customers, 10 types of products, three types of raw materials, six time periods and 10 scenarios.

\subsection{Model validation}

In order to validate the proposed model, we generate 12 instances in different sizes that among these 10 instances, number 8 is the main case problem. The instances are generated based on the case problem and then by merging the similar tests, 12 distinct instances are selected to test the problem. Instances are different in key parameters. For example, if the low-capacity suppliers are considered in instance 1 to be disrupted, the other instances are chosen in a way to focus on disruption of high-capacity suppliers.

The second column represents the instance size in our model. For example, $(3,5,2,3,6,4,7)$ describes a problem with three production/recovery centers, five collection/inspection centers, two disposal centers, 3 types of products, six time periods, four customer zones and seven scenarios. As the results show in Table 2, by comparing total costs of model for both alternatives (model under disruption and without considering disruption respectively), it can be seen that the proposed model has decreased the chain's cost enormously and proves the model efficiency.

\subsection{Sensitivity analysis}

In order to consider the effect of various parameters on optimal solution, several sensitivity analyses were conducted by varying the values of different parameters in the model. According to the nature of problem, 


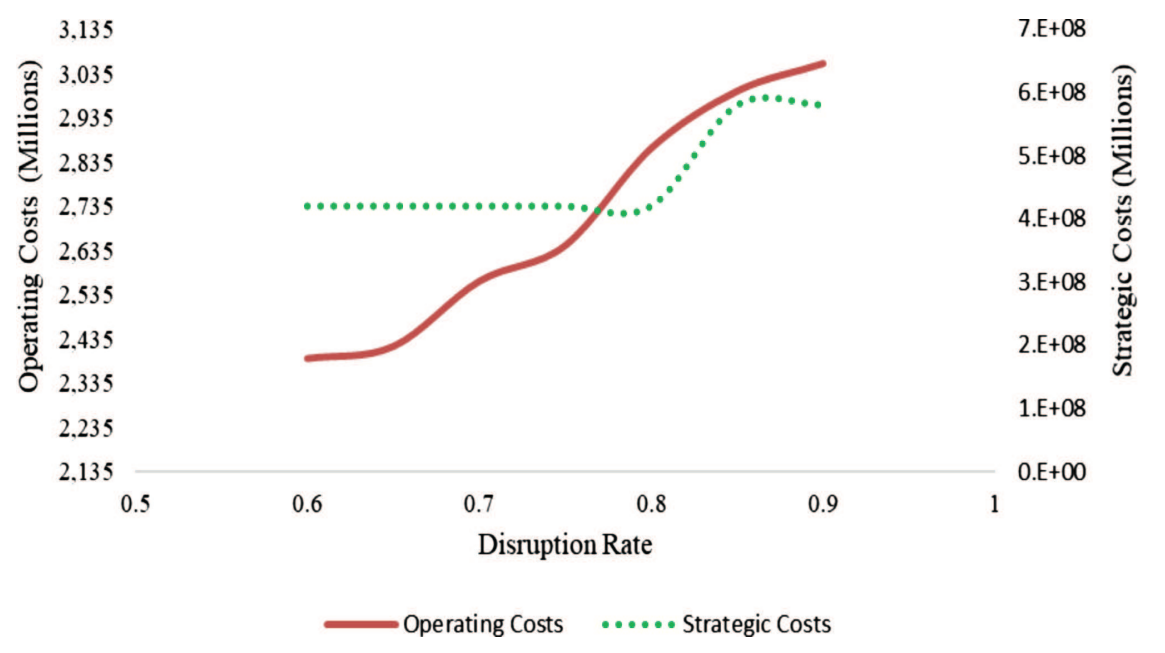

FIGURE 3. The effect of disruption rate on strategic and operational costs.

which aims to reuse products through recycling, the quantity of returned products plays an important role in the proposed system. Production capacity of production centers, disruption percentage and the number of scenarios are the other important parameters. It is considered that production-/recovery centers face complete or partial disruptions. Thus, different scenarios are defined based on the probability of disruption in each production recovery center based on the historical data of disruption in case of Glass industry. As two types of complete and partial disruption is considered in this paper, the scenarios are generated to examine all the possible modes. Analyses and the results are as follows:

\section{Disruption rate}

Figure 3 illustrates that when disruption rate of production center increases, total cost will increase. If disruption ratio is more than 0.8 , strategic costs increase exponentially because of opening new facility.

\section{Production capacity}

By increasing production capacity at production centers, the total cost will decrease. It should be noted that increasing the production capacity needs more spending costs. Nevertheless, increased production capacity cause less strategic and operational costs in order to the reduction of production facilities' number. That means, the total costs will reduce. This issue can be seen in Figure 4.

\section{Returned and final product coefficients in demand function}

As it is obvious in Figure 5, when reverse product's coefficient increases, the objective function has an increase about 0.9 that it is excusable due to the positive price coefficient of reverse products, and the demand increases consequently. In addition, as being seen in the first diagram an increase about 0.8 and 0.85 in the objective function make great increases. But, gradually by making more increments, this coefficient will lose its proficiency since there are some limitations on collecting reverse products in a way that increasing it to 0.95 will have no effect on demand and supply chain profit, consequently.

Due to the Figure 5, increasing the final product's coefficient, demand function will decrease little by little in order to the negative coefficient of final product's price in demand function. Considering that some percent of product's sale is some part of raw material, supply chain's costs increase and the profit will decrease, consequently. 


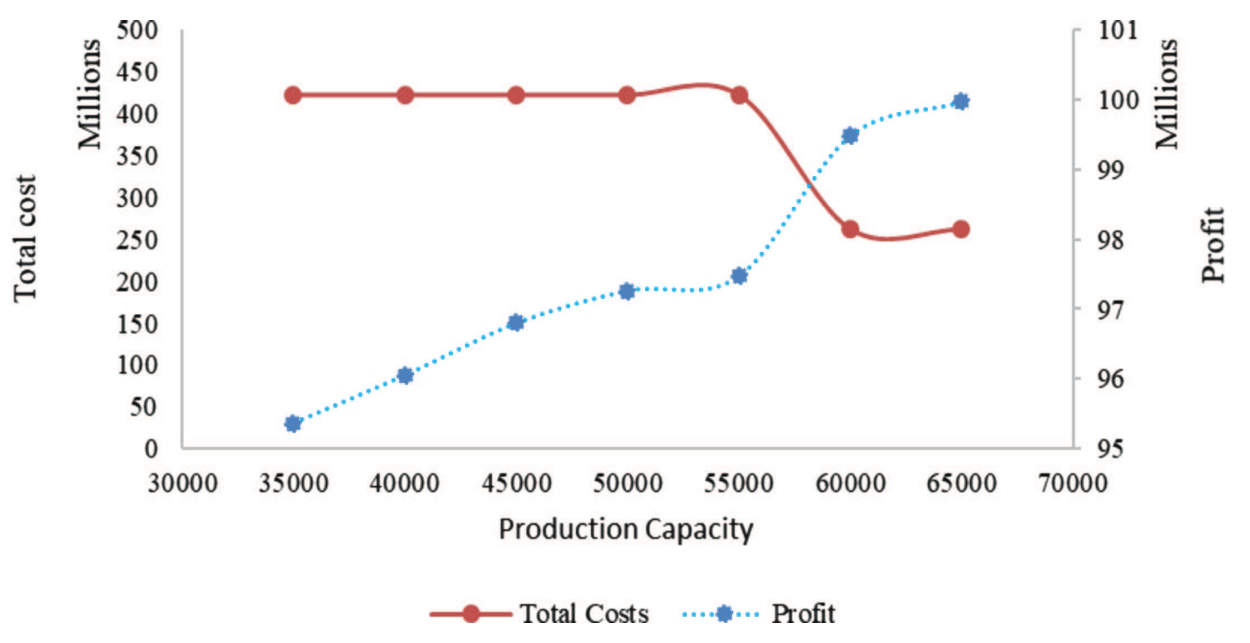

Figure 4. Changes of the total cost by changing production capacity.

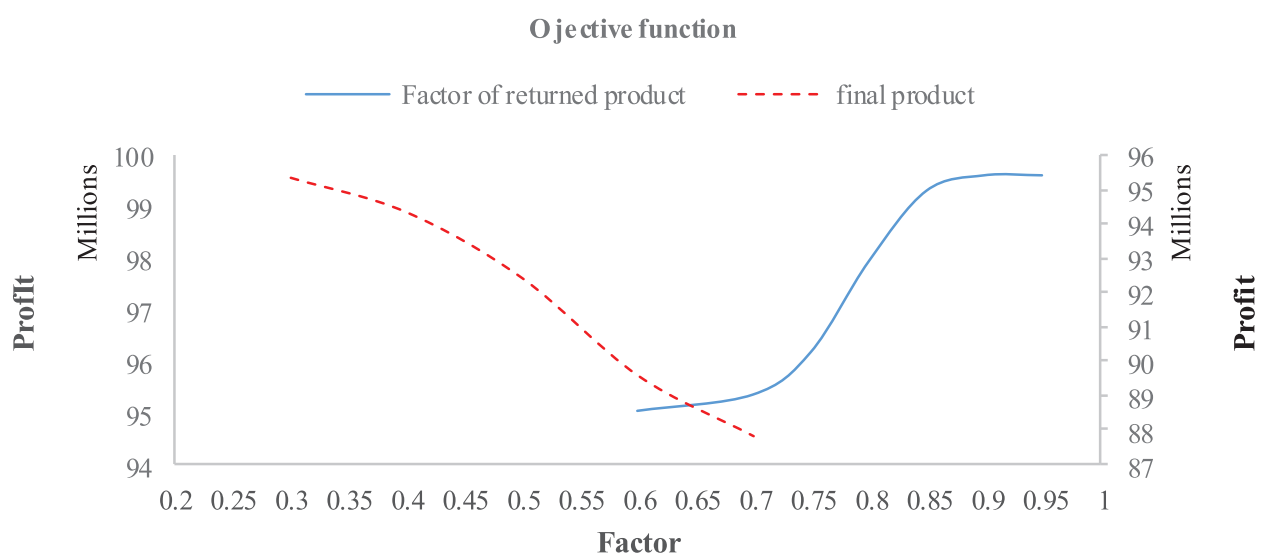

FigURE 5. Effect of variation for returned and final product coefficient in demand function.

\section{Conclusion}

This article presents a demand function for determining the price of final and returned products along with an optimization model for CLSND problem. As facility disruption can enormously affect the whole supply chains, the proposed model incorporates random disruption scenarios. The objective function of the model is to maximize supply chain total profits where the cost terms entailing costs of location and transportation. In order to investigate application of the model in real-world industrial cases, we applied data of a real company in glass industry. In this paper, the resilience concept is presented by considering disruption risks in a CLSCN. Then, some sensitivity analyses were done on the proposed model to evaluate its efficiency. The effects of disruption and implementing flexible strategies on the CLSC showed by the result of analyses. Finally, it can be said that the main contributions of the current paper is considering the price of returned products and disruption risks, simultaneously. The present paper differs from the existing literature in the field of CLSC network design by considering risks of disruption and optimization of final and returned products' prices. More specifically, the model takes the risks of disruption into consideration in designing phase of a multi-period and multi-product CLSC network design. 
For future researches, inherent uncertainty of input data (i.e. demand or returned products) can be considered. To cope with this uncertainty, stochastic programming or robust optimization approach can be challenging methods. Another direction for future research is accounting supply risks. Moreover, applying exact or heuristic solution methods seem necessary when the size of problem and number of disruption scenarios increases.

\section{REFERENCES}

[1] E. Ahmadzadeh and B. Vahdani, A location-inventory-pricing model in a closed loop supply chain network with correlated demands and shortages under a periodic review system. Comput. Chem. Eng. 101 (2017) 148-166.

[2] S.H. Amin and G. Zhang, A multi-objective facility location model for closed-loop supply chain network under uncertain demand and return. Appl. Math. Modell. 37 (2013) 4165-4176.

[3] M.-B. Aryanezhad, S.G. Jalali and A. Jabbarzadeh, An integrated supply chain design model with random disruptions consideration. Afr. J. Bus. Manage. 4 (2010) 2393.

[4] N. Azad and H. Davoudpour, Designing a stochastic distribution network model under risk. Int. J. Adv. Manuf. Technol. 64 (2013) 23-40.

[5] N. Azad, G.K. Saharidis, H. Davoudpour, H. Malekly and S.A. Yektamaram, Strategies for protecting supply chain networks against facility and transportation disruptions: an improved Benders decomposition approach. Ann. Oper. Res. 210 (2013) $125-163$.

[6] E. Bazan, M.Y. Jaber and S. Zanoni, A review of mathematical inventory models for reverse logistics and the future of its modeling: an environmental perspective. Appl. Math. Modell. 40 (2016) 4151-4178.

[7] E. Dehghani, M.S. Jabalameli, A. Jabbarzadeh and M.S. Pishvaee, Resilient solar photovoltaic supply chain network design under business-as-usual and hazard uncertainties. Comput. Chem. Eng. 111 (2018) 288-310.

[8] N. Demirel, E. Özceylan, T. Paksoy and H. Gökçen, A genetic algorithm approach for optimising a closed-loop supply chain network with crisp and fuzzy objectives. Int. J. Prod. Res. 52 (2014) 3637-3664.

[9] M. Esmaeilikia, B. Fahimnia, J. Sarkis, K. Govindan, A. Kumar and J. Mo, A tactical supply chain planning model with multiple flexibility options: an empirical evaluation. Ann. Oper. Res. 2 (2014) 429-454.

[10] M. Farrokh, A. Azar, G. Jandaghi and E. Ahmadi, A novel robust fuzzy stochastic programming for closed loop supply chain network design under hybrid uncertainty. Fuzzy Sets Syst. 341 (2018) 69-91.

[11] M. Fleischmann, P. Beullens, J.M. Bloemhof-Ruwaard and L.N. Wassenhove, The impact of product recovery on logistics network design. Prod. Oper. Manage. 10 (2001) 156-173.

[12] M. Ghomi-Avili, S.G.J. Naeini, R. Tavakkoli-Moghaddam and A. Jabbarzadeh, A fuzzy pricing model for a green competitive closed-loop supply chain network design in the presence of disruptions. J. Cleaner Prod. 188 (2018) 425-442.

[13] A. Hasani and A. Khosrojerdi, Robust global supply chain network design under disruption and uncertainty considering resilience strategies: a parallel memetic algorithm for a real-life case study. Transp. Res. Part E: Logistics Transp. Rev. $\mathbf{8 7}$ (2016) $20-52$.

[14] S. Hatefi and F. Jolai, Robust and reliable forward-reverse logistics network design under demand uncertainty and facility disruptions. Appl. Math. Modell. 38 (2014) 2630-2647.

[15] S. Hatefi, F. Jolai, S. Torabi and R. Tavakkoli-Moghaddam, A credibility-constrained programming for reliable forward-reverse logistics network design under uncertainty and facility disruptions. Int. J. Comput. Integr. Manuf. 28 (2015) 664-678.

[16] A. Jabbarzadeh, M. Haughton and A. Khosrojerdi, Closed-loop supply chain network design under disruption risks: a robust approach with real world application. Comput. Ind. Eng. 116 (2018) 178-191.

[17] A. Jabbarzadeh, M. Haughton and F. Pourmehdi, A robust optimization model for efficient and green supply chain planning with postponement strategy. Int. J. Prod. Econ. 214 (2019) 266-283.

[18] E. Keyvanshokooh, M. Fattahi, S. Seyed-Hosseini and R. Tavakkoli-Moghaddam, A dynamic pricing approach for returned products in integrated forward/reverse logistics network design. Appl. Math. Modell. 37 (2013) 10182-10202.

[19] E. Keyvanshokooh, S.M. Ryan and E. Kabir, Hybrid robust and stochastic optimization for closed-loop supply chain network design using accelerated Benders decomposition. Eur. J. Oper. Res. 249 (2016) 76-92.

[20] M. Lalmazloumian, K.Y. Wong, K. Govindan and D. Kannan, A robust optimization model for agile and build-to-order supply chain planning under uncertainties. Ann. OR 240 (2016) 435-470.

[21] Y.-K. Lin, C.-T. Yeh and C.-F. Huang, Reliability evaluation of a stochastic-flow distribution network with delivery spoilage. Comput. Ind. Eng. 66 (2013) 352-359.

[22] O. Listeş and R. Dekker, A stochastic approach to a case study for product recovery network design. Eur. J. Oper. Res. 160 (2005) 268-287.

[23] Z. Lu and N. Bostel, A facility location model for logistics systems including reverse flows: the case of remanufacturing activities. Comput. Oper. Res. 34 (2007) 299-323.

[24] E. Özceylan, T. Paksoy and T. Bektaş, Modeling and optimizing the integrated problem of closed-loop supply chain network design and disassembly line balancing. Transp. Res. Part E: Logistics Transp. Rev. 61 (2014) 142-164.

[25] M. Pishvaee and S. Torabi, A possibilistic programming approach for closed-loop supply chain network design under uncertainty. Fuzzy Sets Syst. 161 (2010) 2668-2683.

[26] M.S. Pishvaee, R.Z. Farahani and W. Dullaert, A memetic algorithm for bi-objective integrated forward/reverse logistics network design. Comput. Oper. Res. 37 (2010) 1100-1112. 
[27] M.S. Pishvaee, M. Rabbani and S.A. Torabi, A robust optimization approach to closed-loop supply chain network design under uncertainty. Appl. Math. Modell. 35 (2011) 637-649.

[28] L. Qi, Z.-J.M. Shen and L.V. Snyder, The effect of supply disruptions on supply chain design decisions. Transp. Sci. 44 (2010) $274-289$.

[29] Q. Qiang, K. Ke, T. Anderson and J. Dong, The closed-loop supply chain network with competition, distribution channel investment, and uncertainties. Omega 41 (2013) 186-194.

[30] M. Ramezani, M. Bashiri and R. Tavakkoli-Moghaddam, A robust design for a closed-loop supply chain network under an uncertain environment. Int. J. Adv. Manuf. Technol. 66 (2013) 825-843.

[31] M. Ramezani, A.M. Kimiagari, B. Karimi and T.H. Hejazi, Closed-loop supply chain network design under a fuzzy environment. Knowl.-Based Syst. 59 (2014) 108-120.

[32] S. Rezapour, R.Z. Farahani, B. Fahimnia, K. Govindan and Y. Mansouri, Competitive closed-loop supply chain network design with price-dependent demands. J. Cleaner Prod. 93 (2015) 251-272.

[33] M.I.G. Salema, A.P. Barbosa-Povoa and A.Q. Novais, An optimization model for the design of a capacitated multi-product reverse logistics network with uncertainty. Eur. J. Oper. Res. 179 (2007) 1063-1077.

[34] N. Tahirov, P. Hasanov and M.Y. Jaber, Optimization of closed-loop supply chain of multi-items with returned subassemblies. Int. J. Prod. Econ. 174 (2016) 1-10.

[35] B. Vahdani and M. Mohammadi, A bi-objective interval-stochastic robust optimization model for designing closed loop supply chain network with multi-priority queuing system. Int. J. Prod. Econ. 170 (2015) 67-87.

[36] B. Vahdani, R. Tavakkoli-Moghaddam, M. Modarres and A. Baboli Reliable design of a forward/reverse logistics network under uncertainty: a robust- $M / M / C$ queuing model. Transp. Res. Part E: Logistics Transp. Rev. 48 (2012) $1152-1168$.

[37] C.J. Vidal and M. Goetschalckx, A global supply chain model with transfer pricing and transportation cost allocation. Eur. J. Oper. Res. 129 (2001) 134-158.

[38] E. Yadegari, H. Najmi, M. Ghomi-Avili and M. Zandieh, A flexible integrated forward/reverse logistics model with random path-based memetic algorithm. Iran. J. Manage. Stud. 8 (2015) 287.

[39] M. Ziari and M.S. Sajadieh, A behavior-based pricing model in retail systems considering vertical and horizontal competition. Comput. Ind. Eng. 152 (2021) 107054.

[40] S. Zokaee, A. Jabbarzadeh, B. Fahimnia and S.J. Sadjadi, Robust supply chain network design: an optimization model with real world application. Ann. Oper. Res. 257 (2017) 15-44.

\section{Subscribe to Open (S2O) A fair and sustainable open access model}

This journal is currently published in open access under a Subscribe-to-Open model (S2O). S2O is a transformative model that aims to move subscription journals to open access. Open access is the free, immediate, online availability of research articles combined with the rights to use these articles fully in the digital environment. We are thankful to our subscribers and sponsors for making it possible to publish this journal in open access, free of charge for authors.

\section{Please help to maintain this journal in open access!}

Check that your library subscribes to the journal, or make a personal donation to the $\mathrm{S} 2 \mathrm{O}$ programme, by contacting subscribers@edpsciences.org

More information, including a list of sponsors and a financial transparency report, available at: https://www. edpsciences.org/en/maths-s2o-programme 